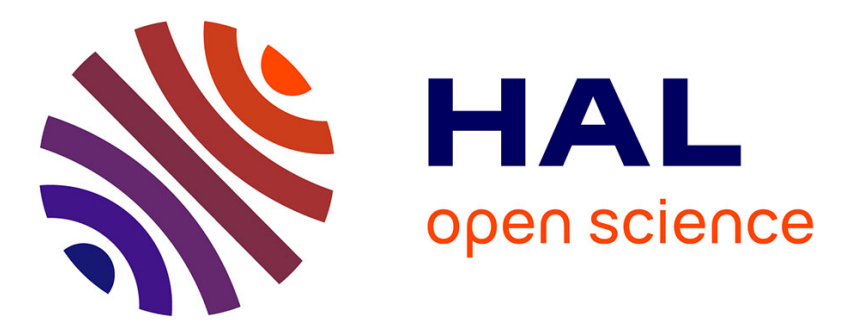

\title{
Calcium-solubilizing sodium thiosulfate failed to improve pulmonary alveolar microlithiasis: Evaluation of calcium content with CT scan
}

\author{
C. Taillé, M.-P. Debray, C. Danel, A. Serhal, P. Pradère, B. Crestani
}

\section{- To cite this version:}

C. Taillé, M.-P. Debray, C. Danel, A. Serhal, P. Pradère, et al.. Calcium-solubilizing sodium thiosulfate failed to improve pulmonary alveolar microlithiasis: Evaluation of calcium content with CT scan. Respiratory Medicine and Research, 2019, 75, pp.10 - 12. 10.1016/j.resmer.2019.04.003 . hal03486579

\author{
HAL Id: hal-03486579 \\ https://hal.science/hal-03486579
}

Submitted on 20 Dec 2021

HAL is a multi-disciplinary open access archive for the deposit and dissemination of scientific research documents, whether they are published or not. The documents may come from teaching and research institutions in France or abroad, or from public or private research centers.
L'archive ouverte pluridisciplinaire HAL, est destinée au dépôt et à la diffusion de documents scientifiques de niveau recherche, publiés ou non, émanant des établissements d'enseignement et de recherche français ou étrangers, des laboratoires publics ou privés.

\section{(ㄷ)(1) $\$$}

Distributed under a Creative Commons Attribution - NonCommerciall 4.0 International 


\title{
Calcium-solubilizing sodium thiosulfate failed to improve pulmonary alveolar microlithiasis: evaluation of calcium content with CT scan.
}

\author{
Camille Taillé $^{(1)}$, Marie-Pierre Debray ${ }^{(2)}$, Claire Danel ${ }^{(3)}$, Ali Serhal ${ }^{(4)}$, \\ Pauline Pradère ${ }^{(5)}$, Bruno Crestani ${ }^{(6)}$.
}

(1) Service de Pneumologie et Centre de Référence Constitutif des Maladies Pulmonaires Rares, Hôpital Bichat, Assistance Publique-Hôpitaux de Paris ; Département Hospitalo-Universitaire FIRE, Université Paris Diderot, INSERM UMR 1152, LabEx Inflamex, Paris, 75018, France. Mail to : camille.taille@aphp.fr

(2) Service de Radiologie, Hôpital Bichat, Assistance Publique-Hôpitaux de Paris, Paris, 75018, France. Mail to : marie-pierre.debray@aphp.fr

(3) Laboratoire de Pathologie, Hôpital Bichat, Assistance Publique-Hôpitaux de Paris, Paris, 75018, France. Mail to : claire.danel@aphp.fr

(4) Service de Radiologie, Hôpital Bichat, Assistance Publique-Hôpitaux de Paris, Paris, 75018, France. Mail to : ali.serhal@ hotmail.com

(5) Service de Pneumologie et Centre de Référence Constitutif des Maladies Pulmonaires Rares, Hôpital Bichat, Assistance Publique-Hôpitaux de Paris, Paris, 75018, France. Mail to : pauline.pradere@gmail.com

(6) Service de Pneumologie et Centre de Référence Constitutif des Maladies Pulmonaires Rares, Hôpital Bichat, Assistance Publique-Hôpitaux de Paris; Département Hospitalo-Universitaire FIRE, Université Paris Diderot, INSERM UMR 1152, LabEx Inflamex, Paris, 75018, France. Mail to : bruno.crestani@aphp.fr 


\section{Corresponding author :}

Prof Camille Taillé, Service de pneumologie, Hôpital Bichat,

46 rue Henri Huchard, 75018, Paris, France

Mail to camille.taille@aphp.fr

Phone: 331402568

Key words: pulmonary alveolar microlithiasis, sodium thiosulfate, lung density, quantitative CT scan.

\section{Abbreviations}

PAM : Pulmonary alveolar microlithiasis

DLCO : lung diffusing capacity for carbon monoxide

CT scan : computerized tomography

STS : sodium thiosulfate

HU : Hounsfield units

SLC34A2 : Solute Carrier Family 34 (Sodium Phosphate), Member 2 
Pulmonary alveolar microlithiasis (PAM) is a rare genetic disease due to mutation of the Solute Carrier Family 34 (Sodium Phosphate), Member 2 (SLC34A2) gene encoding the type IIb sodium phosphate cotransporter in alveolar type II cells (1). Such cells are responsible for the uptake of phosphate released from phospholipids in outdated surfactant. The inability to clear phosphate from the alveolar space explains the formation of calcium phosphate microliths in the alveolar lumen (1). Treatment with corticosteroids, bronchoalveolar lavage and etidronate disodium has failed to prevent disease progression and the development of chronic respiratory insufficiency $(1,2)$. Sodium thiosulfate (STS) is a calcium-chelating and solubilizing agent used in different calcium-related disorders, especially ectopic calcification and calciphylaxis in patients undergoing chronic hemodialysis(3). STS is also evaluated to mitigate chemotherapeutic toxicity and to prevent ischemia-reperfusion injuries (3). It has never been used in PAM.

A 35-year-old non-smoker woman with familial PAM, with a documented mutation in the SLC34A2 gene, was referred for progressive exertional dyspnea. She reported her sister had died due to end-stage respiratory failure 4 years before. Thoracic computerized tomography (CT) scan revealed the typical latest, most severe, radiological phase of PAM, with diffuse micronodules of variable density and diffuse ground-glass opacities associated with intense hyperdensity of calcium type of the pleura, interlobular septa and bronchovascular bundles (Figure 1A). Intra-alveolar accumulation of calcium microliths was confirmed by bronchoalveolar lavage (turbid, with a beige color and many lamellar calcified bodies with a concentric appearance observed with hematoxylin and eosin staining), and by transbronchial biopsies.

As frequently observed, extensive calcium deposits seen on CT scan contrasted with preserved lung volumes on pulmonary function tests and an isolated decrease in lung diffusing capacity for carbon monoxide (DLCO) (58\% of predicted value at first evaluation, 
without any change during a 2 years follow up). No calcifications were observed out of the lung.

Monthly intravenous infusion of sodium thiosulfate (STS) (12.5 g/month) (4) was proposed and started after the patient gave informed consent and with French health authority authorization. The treatment was well tolerated except for mild transient nausea after the infusion. Phosphate, calcium, and bicarbonate blood levels did not change during the treatment. After 9 months of treatment, the patient showed no improvement in dyspnea. DLCO slightly decreased, from $58 \%$ to $51 \%$ predicted, with no change in lung volumes.

Chest CT revealed a marked increase in lung density, related to an increase in lung calcium content, at 6 months after treatment initiation. This was quantified by calculating the mean lung density of the semi-automatically segmented lungs. Particular attention was brought to the separation of calcified pleura from ribs. The left lung mean density was -227 Hounsfield units (HU) before treatment and $-111 \mathrm{HU}$ at 6 months after treatment initiation (Figure 1, B and D). Both the rapid functional impairment, despite modest, contrasting with a previously stable situation, and notable change in lung density led to stopping the treatment. The patient was evaluated for lung transplantation in another center.

This is the first reported case of PAM treated with STS, a cheap and generally well tolerated treatment (5). STS is proposed for ectopic calcifications in end-stage renal failure but also in some cases of connective tissue diseases. Some treatment failures have been reported but no increase in calcium deposits has been described for now. Treatment failures may be related to tissue distribution or administration modalities which may differ according to the disease : a single infusion is given in patients with cyanide poisoning, one infusion every 2 days in patients undergoing haemodialysis, five infusions every month in connective tissue diseases (5). In the present case, STS regimen was less intensive but more convenient for the patient, a housewife living distant from hospital. A rapid increase in calcium deposits, as observed in 
the present case, is unusual in PAM progression. Therefore, we considered it was precipitated by STS and may be related to calcium thiosulfate salts deposition in the alveolar lumen, which are generally removed by haemodialysis in calciphylaxis.

Variable radiological aspects of PAM have been described and subdivided into four evolutionary phases (1). The first phase (precalcific) is described as a small number of non typical, poorly calcified microliths. In the second phase, the lungs are described as "sandy", with diffuse uniformed microliths. When the number and volume of microliths increase, they become granular, confused due to the initial thickening of the interstitial tissue. In advanced cases, or fourth phase, an intense calcification of the interstitium and pleura is observed, thereby leading to an entirely opaque lung, sometime associated with air cysts in the upper lobes.

Clinico-radiological dissociation has been frequently reported in PAM (1) as was observed in our patient. Quantitative CT, used for longitudinal disease monitoring in the context of emphysema or interstitial lung diseases, allows for a more objective and reproducible measure of disease (6). The potential usefulness of quantitative CT as a monitoring tool in PAM has not been previously assessed, especially for evaluating treatment. In some cases, etidronate disodium, a biphosphonate, induced an impressive regression of lung calcifications in PAM (1). However, in cases showing no effect (7), a quantitative evaluation may have helped detect a more subtle effect on calcium content, preceding a clinical benefit. Such quantification may be helpful for early evaluation of treatments for PAM, especially in patients showing little impaired lung function.

Despite monthly injections of STS, we observed a progression of lung calcium deposits. Quantitative lung calcium content evaluation with CT scan was here useful to detect early changes in lung density, whereas lung function was slightly impaired. Quantitative lung CT should be evaluated as a new tool for evaluation of therapeutics in PAM. 


\section{Declaration}

- Ethical approval and consent to participate : STS was given after authorization from the Agence Nationale du Médicament (ANSM). The patient gave informed consent for the treatment and for publication

- Consent for publication : the patient gave written informed consent

- Competing interests : The authors declare that they have no competing interests

- Funding source : no funding

- Acknowledgments: We thank Laura Smales for English edition. 


\section{References}

1. Saito A, McCormack FX. Pulmonary Alveolar Microlithiasis. Clin Chest Med. 2016;37(3):441-8.

2. Castellana G, Castellana G, Gentile M, Castellana R, Resta O. Pulmonary alveolar microlithiasis: review of the 1022 cases reported worldwide. Eur Respir Rev Off J Eur Respir Soc. 2015 Dec;24(138):607-20.

3. Auriemma M, Carbone A, Di Liberato L, Cupaiolo A, Caponio C, De Simone C, et al. Treatment of cutaneous calciphylaxis with sodium thiosulfate: two case reports and a review of the literature. Am J Clin Dermatol. 2011 Oct 1;12(5):339-46.

4. Hall AH, Dart R, Bogdan G. Sodium thiosulfate or hydroxocobalamin for the empiric treatment of cyanide poisoning? Ann Emerg Med. 2007 Jun;49(6):806-13.

5. Nigwekar SU, Brunelli SM, Meade D, Wang W, Hymes J, Lacson E. Sodium thiosulfate therapy for calcific uremic arteriolopathy. Clin J Am Soc Nephrol CJASN. 2013 Jul;8(7):1162-70.

6. Ash SY, Harmouche R, Vallejo DLL, Villalba JA, Ostridge K, Gunville R, et al. Densitometric and local histogram based analysis of computed tomography images in patients with idiopathic pulmonary fibrosis. Respir Res. 2017 07;18(1):45.

7. Cakir E, Gedik AH, Özdemir A, Buyukpınarbasili N, Bilgin M, Ozgen IT. Response to Disodium Etidronate Treatment in Three Siblings with Pulmonary Alveolar Microlithiasis. Respir Int Rev Thorac Dis. 2015;89(6):583-6. 


\section{Figure legends}

Figure 1. Chest $C T$ scan before $(A, B, D)$ and after $(C, E) 6$ months of sodium thiosulfate treatment for pulmonary alveolar microlithiasis (PAM). Chest CT scan in the axial plane (A, lung window) shows diffuse micronodules of variable density and diffuse ground-glass opacities associated with septal and pleural thickening. The latter show intense hyperdensity, of calcium type on the mediastinal window (D), typical of the latest, most severe, radiological phase of alveolar microlithiasis. There is impressive extent of calcium densities in the lower and posterior lung zones at 6 months, as depicted on axial images (D, E, mediastinal window). $3 \mathrm{D}$ volume rendering of the left lung $(\mathrm{B}, \mathrm{C})$ shows the extent of calcium deposits and particularly their septal distribution (densities superior to $110 \mathrm{HU}$ are depicted in grey and lower densities are depicted in blue). The left lung has been semi-automatically segmented and the mean lung density calculated from the density histogram analysis of the all lung. Mean lung density has decreased from -227 to -111 HU and lung volume slightly decreased between the two time points (mean lung density in healthy individuals is usually about -800 UH). Such change in lung density reflects an increase in calcium content. 

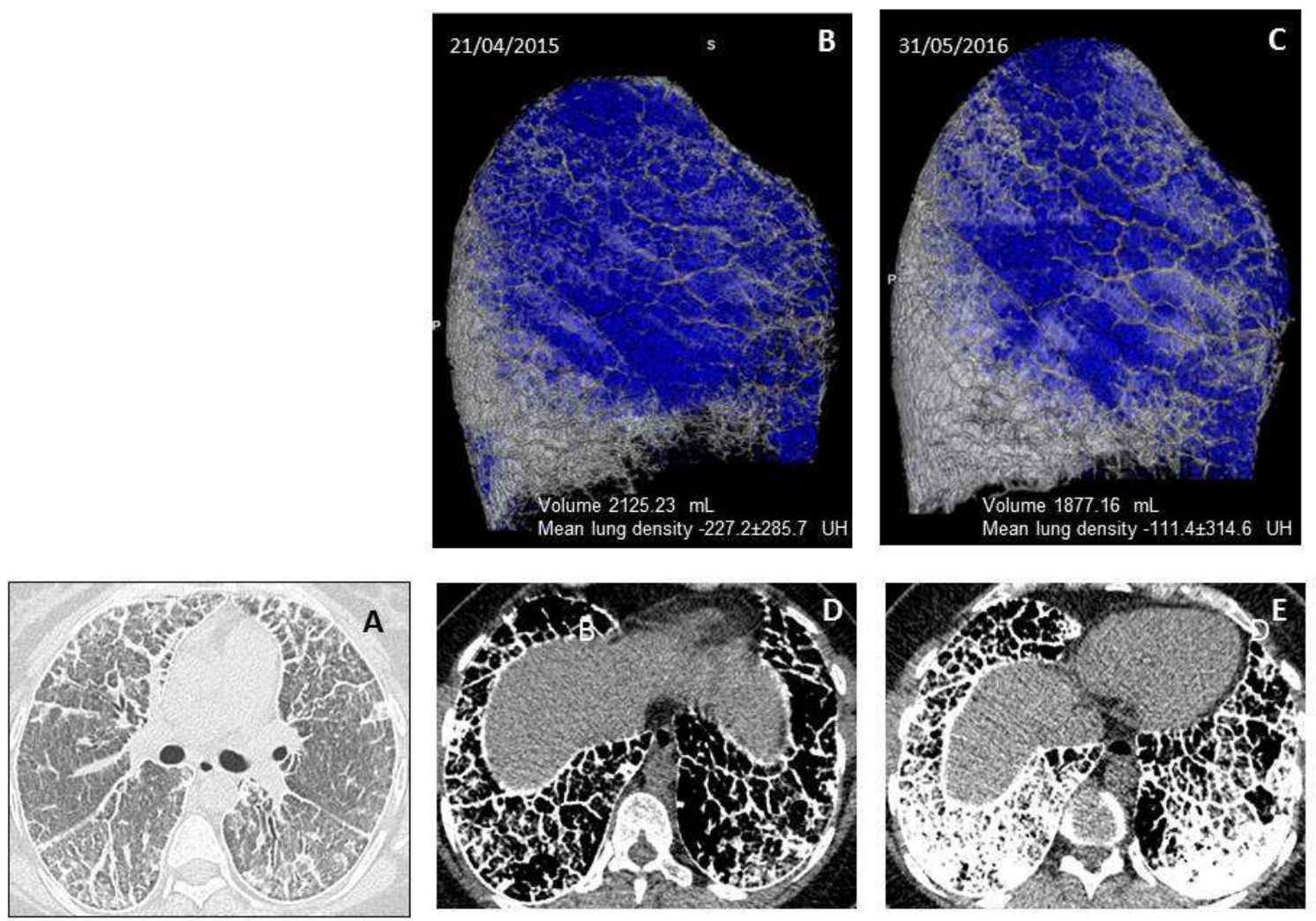

Figure 1 